\title{
Study of Serum Magnesium Levels in Types 2 Diabetes Mellitus
}

\author{
A.G. Kulkarni ${ }^{1}$, Sachin K. Shendge ${ }^{2}$, Vikramaditya Shinde ${ }^{3}$ \\ ${ }^{1,2,3}$ M.G.M. Medical College \& Hospital, Aurangabad
}

\begin{abstract}
:
Background And Objectives: Diabetes mellitus was one of the most common metabolic disorder and leading cause of death and disability in the world. The incidence of diabetes was increasing in India and globally. Several studies have shown that low serum magnesium concentrations in Type 2 diabetics compared to healthy controls. Magnesium depletion has a negative impact on glucose homeostasis and insulin sensitivity in patients with Type 2 diabetes. Magnesium deficiency can lead to development of complications such as retinopathy, thrombosis and hypertension. Hence this study was conducted at Tertiary care center in Aurangabad Maharashtra.

Methods: A study was done in randomly chosen 100 Type 2 diabetic patients, and 100 non diabetic age / sex matched controls age group 30 to 70 years attending diabetic clinic at M.G.M. Medical College And Hospital Aurangabad. All patients and controls underwent thorough clinical examination and estimation of serum magnesium, FBS, PPBS, lipid profile and urea, creatinine levels.

Results: $37 \%$ of diabetic patients had low serum magnesium levels $\left(\mathrm{Mg}^{2+}\right.$ level $\left.\leq 1.5 \mathrm{mg} / \mathrm{dL}\right)$ and $9 \%$ of controls had low serum magnesium levels $\left(\mathrm{Mg}^{2+}\right.$ level $\left.\leq 1.5 \mathrm{mg} / \mathrm{dL}\right)$. The mean serum magnesium levels were $1.96=0.54 \mathrm{mg} / \mathrm{dL}$ and $2.375 \pm 0.449 \mathrm{mg} / \mathrm{dL}$, in diabetics and controls respectively $(p$ value $<0.0001$ Highly significant). There is negative co relationship between Sr.Mg Levels and hypertension and there was also found to be negative correlation between $M g$ and retinopathy.

In the study hypomagnesaemia $\left(\mathrm{Mg}^{2+}\right.$ level $\left.\leq 1.5 \mathrm{mg} / \mathrm{dl}\right)$ is correlating with hypertension hence there is an association between hypertension and serum $\mathrm{Mg}^{2+}$ level ( $p=0.018$ highly significant). Hypomagnesaemia $(\mathrm{Mg} 2+$ Level $\leq 1.5 \mathrm{mg} / \mathrm{dL})$ is correlating with retinopathy In this study hence there is an association between retinopathy and serum $M^{\text {g2 }}+$ level p:0.041 significant)
\end{abstract}

Interpretation And Conclusion: This study demonstrated that Low $\mathrm{Mg}^{2+}$ status is common in Type 2 diabetes mellitus patients when compared to non diabetic controls. It may be prudent in clinical practice to periodically monitor plasma $\mathrm{Mg}^{2+}$ concentration in diabetic patients. If plasma $\mathrm{Mg}^{2+}$ is low, an intervention to increase dietary intake of magnesium maybe beneficial.

Keywords: Diabetes mellitus, magnesium, hypomagnesaemia, hypertension, retinopathy, dyslipidemia.

\section{Introduction}

Diabetes mellitus is one of the most common metabolic disorder and leading cause of death and disability in the world. The incidence of diabetes is increasing globally and in India. W.H.O has declared India as the global capital of diabetes. In 1997 WHO estimate of the prevalence of the diabetes in adults showed an expected rise of $>120 \%$ from 135 million in 1995 to 300 million in 2025 .

India leads in the world with its largest number of diabetes subjects as compared with any other given country It has been estimated that presently 19.4 million individuals are affected by diabetes and these numbers are expected to increase to 57.2 million by the year $2025(1 / 6 \text { th of world total })^{1}$

Magnesium depletion has a negative impact on glucose homeostasis and insulin sensitivity in patients with Type 2 diabetes. Magnesium deficiency can lead to development of complications such as retinopathy, thrombosis and hypertension. Several studies have shown that high prevalence of low serum magnesium concentrations in Type 2 diabetes when compared to healthy controls.

Magnesium deficiency may result in failure to inhibit entry of calcium into myocardial cells, failure to extrude calcium from the cells, formation of crystals in mitochondria and failure of sarcoplasmic reticulum to sequester excess calcium. ${ }^{2}$

Many studies have shown that both mean plasma and intracellular free magnesium levels are lower in patients with diabetes than in the general population. This magnesium deficiency, which may take the form of a chronic latent magnesium deficit rather than clinical hypomagnesaemia, may have clinical importance because the magnesium ion is a crucial cofactor for many enzymatic reactions involved in metabolic processes.

Many studies show that mean plasma levels are lower in patients with both type 1 and type 2 diabetes compared with non-diabetic control subjects. The concentration of intracellular free magnesium in erythrocytes is a more sensitive marker in people with diabetes and insulin resistance than are plasma levels of magnesium. Decreased 
levels of free intracellular magnesium in erythrocytes have been reported in the majority of patients with type 2 diabetes.

Resnick and associates suggest that extracellular and intracellular magnesium deficiency is typical in chronic, stable, mild type 2 diabetes and may be a strong predisposing factor for the development of the excess cardiovascular morbidity associated with diabetes. These investigators showed that the levels of serum ionized magnesium and erythrocyte intracellular free magnesium were significantly lower in 22 untreated patients with type 2 diabetes and mild hyperglycemia than they were in 30 healthy control subjects $(\mathrm{P}<.001)$. Serum total magnesium was not reduced.

It is observed that low serum magnesium concentration and poor magnesium status are common in Type 2 diabetes mellitus. Preventing hypomagnesaemia in diabetes by supplementing magnesium may be helpful in increasing insulin sensitivity and delaying the development of late diabetic complications.

Therefore, the aim of the study is to compare the serum magnesium concentrations in patients with Type 2 diabetes and non-diabetic controls to assess its impact on complications.

\section{Source of data :}

\section{Materials And Methods}

Randomly chosen 100 Type 2 diabetic patients, and 100 non diabetic age/sex matched controls attending diabetic clinic at M.G.M. Medical College And Hospital Aurangabad. Between June 2011 to September 2013 were included in his study.

\section{Method Of Collection Of Data:}

In this study 112 Type 2 diabetic patients and 108 controls were studied, among them 12 diabetic patients were excluded from the study due to increased creatinine levels and 8 controls were excluded from current study due to impaired blood glucose levels and elevated urea and creatinine levels, after exclusion ,100 Type 2 diabetic patients and 100 age and sex matched non diabetic controls in the age group of 30 to 70 years who were fit in inclusion criteria were studied.

Detailed history and clinical examination and biochemical investigations included Patients age ,sex, Duration of diabetes mellitus, Details regarding presenting complaints, Past history of any Other diseases, History of comorbid diseases like hypertension, Ischemic heart disease.

Family history of Diabetes and Hypertension taken and Detailed general. physical examination conducted. Pulse, Blood Pressure, Respiratory Rate, Temperature ,Height, Weight, BMI and detailed systemic examination was carried out in all patients and controls. Fundoscopic examination done in all patients and controls. 12 leads ECG done in all diabetic patients.

\section{Biochemical Tests Done Among Diabetic Patients:}

a) FBS and PPBS.

b) Serum magnesium Levels.

c) $\mathrm{HbA1C}$.

d) Lipid profile.

e) Blood Urea and Serum Creatinine

\section{Biochemical Tests Done Among Non Diabetic Controls:}

FBS and PPBS.

Serum magnesium levels.

Blood Urea and Serum Creatinine.

\section{Inclusion Criteria:}

All cases of Type 2 diabetes mellitus patients and non diabetic controls aged between 30 to 70 years attending diabetic clinic, at M.G.M. Medical college and hospital Aurangabad.

\section{Exclusion Criteria:}

- Patients with renal failure.

- Patients who suffered acute myocardial infarction in last six months

- Patients on diuretics.

- Patients with history of alcohol abuse.

- Patients on magnesium supplements/magnesium containing antacids.

- Mal absorption.

- Chronic diarrhea. 
Study Design:

One and half year observational comparative study.

\section{Sample Size:}

100 patients of Type 2 diabetes mellitus and

100 non diabetic age/sex matched controls, aged between 30yrs to 70yrs

\section{Method of Estimation Of Serum Magnesium \\ Principle of the test:}

It is an enzymatic end point method. Principle of reaction is that, the Calmagite combines with the magnesium to form a red complex in alkaline solution which is measured at 520 run.

Reagent is in liquid form ready for use.

A magnesium standard is provided with the reagent.

Wave length : $520 \mathrm{~nm}$.

Temperature : $\quad 370 \mathrm{c}$

Cuvette : $\quad 10 \mathrm{~nm}$ path length

Incubation : 5 minutes

Standard: $\quad 2 \mathrm{mg} / \mathrm{dL}$

Kit used in this study was RAICHEM's Magnesium liquid reagent The normal serum magnesium level is ranging from $1.8 \mathrm{mg} / \mathrm{Dl}$ to $2.9 \mathrm{mg} / \mathrm{dL}$. Serurn magnesium levels $<1.5 \mathrm{mg} / \mathrm{dL}$ is considered as low magnesium level in this study.

\section{Result And Observation}

In this study Maximum number of patients were in the age group of 51-60 ie. about $47 \%$ of patients followed by $26 \%$ between $41-50$ years, $21 \%$ between $61-70$ years $6 \%$ patients between $30-40$ years, In Diabetic group 51 patients were males and 49 females. In control group 58 are males and 42 are females. In this study 43 patients were having DM since 0.5 to 5 years and 37 patients were having DM since 5 to 10 years and only 20 patients were having DM since more than 10 years. maximum patients fall in the group of 0.5 to 5 years.

The fasting blood sugar in diabetics ranged from $80 \mathrm{mg} / \mathrm{dl}$ to $243 \mathrm{mg} / \mathrm{dL}$ with a mean of $124.1+27.9 \mathrm{mg} / \mathrm{dL}$, whereas in controls it ranged from $75 \mathrm{mg} / \mathrm{dL}$ to $105 \mathrm{mg} / \mathrm{dL}$ with a mean of $93.6+5.42 \mathrm{mg} / \mathrm{dL}$.

The PPBS in diabetics ranged from 100 to $361 \mathrm{mg} / \mathrm{dL}$ with a mean of $210.4+47.5 \mathrm{mg} / \mathrm{dL}$, whereas in controls it ranged from $120 \mathrm{mg} / \mathrm{dL}$ to $152 \mathrm{mg} / \mathrm{dL}$ with a mean of $136.32 \pm 7.59 \mathrm{mg} / \mathrm{dL}$.

Mean $\mathrm{HbA}_{1} \mathrm{c}$ levels among diabetics was ranging from 4.12 to $10.8 \%$ with a mean $\pm \mathrm{SD}$ of $7.061 \pm 1.211 \%$.

In diabetics mean serum magnesium level is $1.96+0.54 \mathrm{mg} / \mathrm{dL}$ and in non diabetic controls $2.375+0449 \mathrm{mg} / \mathrm{dL}$. Mean serum magnesium levels is lower in diabetic patients.

Out of 100 diabetic patients 37 patients had low magnesium levels $\left(\mathrm{Mg}^{2+} \leq 1.5 \mathrm{mg} / \mathrm{dL}\right)$ and in controls only 9 patients had low magnesium levels.

out of 100 diabetics 13 patients had Neuropathy and 87 patients not having Neuropathy.

out of 100 diabetics 17 patients had retinopathy and 83 patients not having retinopathy.

Hypomagnesaemia $\left(\mathrm{mg}^{2+}\right.$ level $\left.=1.5 \mathrm{mg} / \mathrm{dL}\right)$ did not correlated with duration of diabetes mellitus. Hence there is no association between duration of DM and serum $\mathrm{Mg}^{2+}$ level ( $\mathrm{p}>0.05$ not significant.)

low magnesium level $\left(\mathrm{Mg}^{+2}\right.$ level $\left.=1.5 \mathrm{mg} / \mathrm{dL}\right)$ was correlated with Hypertension. Hence there is an association between Hypertension and serum $\mathrm{Mg}^{2+}$ level ( $\mathrm{P}=0.018$ Highly significant), it means that patients having low magnesium levels had the risk of developing Hypertension low magnesium level $\left(\mathrm{Mg}^{+2} \mathrm{level}=1.5 \mathrm{mg} / \mathrm{dL}\right) \mathrm{did}$ not correlated with development of Neuropathy. Hence there is no association between. Neuropathy and serum $\mathrm{Mg}^{2+}$ level ( $\mathrm{p}>0.05$ ) low magnesium level $\left(\mathrm{Mg}^{+2}\right.$ level $\left.=1.5 \mathrm{mg} / \mathrm{dL}\right)$ is correlating with Retinopathy in this study. Hence there is significant correlation between Retinopathy and serum $\mathrm{Mg}^{2+}$ level ( $\mathrm{p}<0.041$ significant.)

GRAPH 1

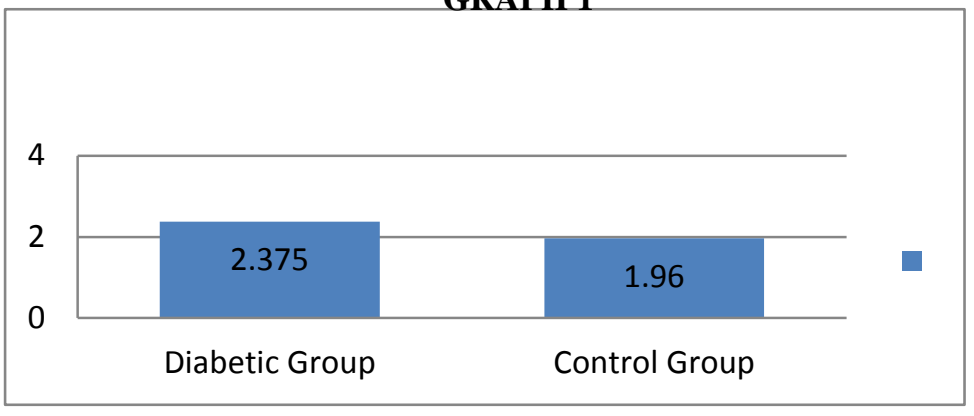


Mean serum magnesium level in type 2 diabetes mellitus patients and non diabetic controls.

Graph 2

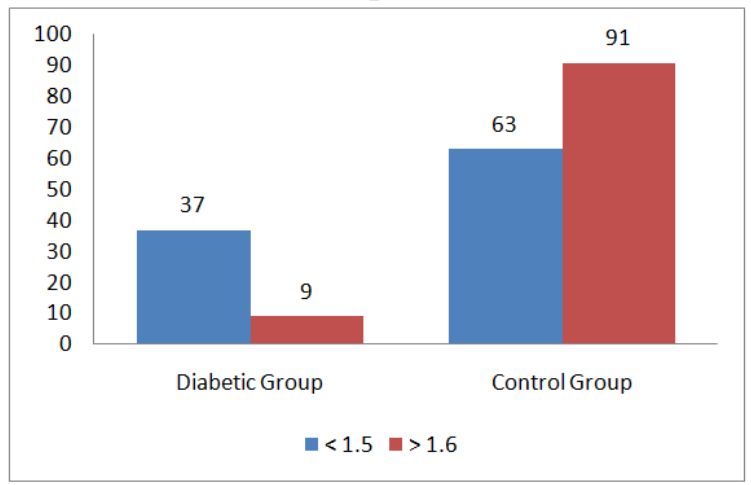

Prevalence of Low serum magnesium levels in Type 2DM patients and controls.

Table No. 1 Diabetes patients with Neuropathy

\begin{tabular}{|c|c|}
\hline Type 2 DM patients with Neuropathy & Type 2 DM patients without Neuropathy \\
\hline 13 & 87 \\
\hline
\end{tabular}

Table No. 2 Diabetes patients with Retinopathy

\begin{tabular}{l|l} 
Type 2 DM patients with Retinopathy & Type 2 DM patients without Retinopathy \\
\hline
\end{tabular} 17 83

Table No. 3 Relation Between Serum magnesium levels and duration of DM.

\begin{tabular}{|c|c|c|c|}
\hline \multirow{2}{*}{$\begin{array}{l}\text { Duration of DM In } \\
\text { years }\end{array}$} & \multicolumn{2}{|c|}{$\mathrm{Mg}^{2+}$ level } & \multirow[t]{2}{*}{ Mean+SD(in mg /dL) } \\
\hline & $\leq 1.5$ & $\geq 1.6$ & \\
\hline$<0.5$ & 0 & 0 & \multirow{4}{*}{$\begin{array}{l}X^{2}=0.924 \\
p=0.63^{*}\end{array}$} \\
\hline $0.5-5$ & 14 & 29 & \\
\hline $5-10$ & 14 & 23 & \\
\hline$>10$ & 09 & 11 & \\
\hline Total & 37 & 63 & \\
\hline
\end{tabular}

Table No. 4 Relation between serum magnesium levels and Hypertension.

\begin{tabular}{|l|ll|l|}
\hline \multirow{2}{*}{ Hyptertension } & \multicolumn{2}{|c|}{$\begin{array}{c}\mathrm{Mg}^{2+} \text { level } \\
\text { (in mg/dL) }\end{array}$} & Statistical test applied \\
\cline { 2 - 3 } & $\leq 1.5$ & $\geq 1.6$ & \\
\hline Yes & 18 & 16 & \multirow{2}{*}{$\mathrm{X}^{2}=5.616$} \\
$\mathrm{p}=0.18^{* *}$
\end{tabular}

Table No. 5 Relation between serum magnesium levels and Neuropathy.

\begin{tabular}{|l|c|c|c|}
\hline \multirow{2}{*}{ Neuropathy } & \multicolumn{2}{|c|}{$\begin{array}{c}\mathrm{Mg}^{2+} \text { level } \\
\text { (in mg/dL) }\end{array}$} & Statistical test applied \\
\cline { 2 - 3 } & $\leq 1.5$ & $\geq 1.6$ & \\
\hline Yes & 5 & 8 & \multirow{2}{*}{$\mathrm{X}^{2}=0.014$} \\
No. & 32 & 55 & $0.907^{* *}$ \\
\hline Total & 37 & 63 & \\
\hline
\end{tabular}

Table No. 6 Relation between serum magnesium levels and Retinopathy.

\begin{tabular}{|l|c|c|c|}
\hline \multirow{2}{*}{ Retinopathy } & \multicolumn{2}{|c|}{$\begin{array}{c}\mathrm{Mg}^{2+} \text { level } \\
\text { (in mg/dL) }\end{array}$} & \\
\cline { 2 - 3 } & $\leq 1.5$ & $\geq 1.6$ & \\
\hline Yes & 10 & 07 & \multirow{2}{*}{$\mathrm{X}^{2}=4.185$} \\
\hline No. & 27 & 56 & $\mathrm{p}=0.041^{* *}$ \\
\hline Total & 37 & 63 & \\
\hline
\end{tabular}

\section{Conclusion}

This study demonstrated that, Low magnesium status is common in type 2 diabetes mellitus patients when compared to non diabetic controls Because $\mathrm{Mg}^{2+}$ depletion reduces insulin sensitivity and may increase risk of secondary complications, like retinopathy, hypertension it may be prudent in clinical practice to periodically monitor plasma $\mathrm{Mg}^{2+}$ concentrations in diabetic patients. If plasma $\mathrm{Mg}^{2+}$ is low, an intervention to increase dietary intake of magnesium may be beneficial. 


\section{References}

[1]. King H, Aubert RE, Herman WH. Global burden of diabetes, 1995-2025- prevalence numerical estimate and projections. Diabetes Care 1998; 21:1414-31.

[2]. Bursch GE, Gibbs TD. Importance of magnesium deficiency in cardiovascular disease. Am Heart J 1977;94:649-654.

[3]. Resnick LM, Altura BT, Gupta RK, Larsh JH, Alderman MH, Altura BM. Intracellular and extracellular magnesium depletion in type 2 diabetes mellitus. Diabetologia 1993;36:767-770. 